\title{
HISTAMINA EM CONSERVAS DE SARDINHA
}

\author{
Francislene Bernardes Tebalti do Carmo, ${ }^{1}$ Eliane Teixeira Mársico, ${ }^{2}$ \\ Sérgio Carmona São Clemente, ${ }^{2}$ Renato Poubel do Carmo ${ }^{3}$ e Mônica Queiroz de Freitas ${ }^{2}$
}

1. Veterinária autônoma

2. Departamento de Tecnologia dos Alimentos, Faculdade de Veterinária, UFF

3. Ministério da Agricultura Pecuária e Abastecimento, fiscal agropecuário.

\section{RESUMO}

O presente estudo avaliou a presença de histamina em 122 amostras de sardinha em conserva, produzidas com três diferentes espécies, por três indústrias, localizadas nos municípios de São Gonçalo e Niterói. As amostras foram divididas em cinco lotes com exemplares de sardinhas provenientes da Venezuela (Sardinella aurita), Marrocos ( $S$. pilchardus) e do Brasil ( $S$. brasiliensis). Avaliou-se a qualidade inicial da matéria-prima por meio de parâmetros sensoriais e pelo teor de histamina utilizando- se o método de cromatografia em camada delgada. As amostras oriundas da Venezuela e Marrocos apresentaram valores abaixo de $5 \mathrm{mg} / 100 \mathrm{~g}$ e as nacionais, valores semelhantes ou superiores a 10 $\mathrm{mg} / 100 \mathrm{~g}$. Conclui-se que há necessidade de um maior controle e monitorização da temperatura da sardinha desde a captura até o processamento, para que o produto final apresente boa qualidade e não represente perigo de intoxicação ao consumidor.

PALAVRAS-CHAVES: Conserva, histamina, qualidade, sardinha.

\section{ABSTRACT}

\section{HISTAMINE IN CANNED SARDINES}

In this study, the presence of histamine in 122 samples of canned sardines produced with three different species by three industries located in the municipalities of Sao Goncalo and Niteroi was evaluated. The samples were divided into five lots with copies of sardines from Venezuela (Sardinella aurita), Morocco (S. pilchardus) and Brazil (S. brasiliensis). The initial quality of raw material was evaluated by sensorial parameters and by the

KEY WORDS: Canned fish, histamine, quality, sardines.

\section{INTRODUÇÃO}

A histamina [4-(2aminoetil)imidazol] é uma diamina biogênica primária e heterocíclica, não volátil, termoestável, presente no produto até mesmo após processo de esterilização comercial, caso tenha histamine level using a semi-quantitative method of thin-layer chromatography. The results of the samples from Venezuela and Morocco showed values below $5 \mathrm{mg} / 100 \mathrm{~g}$, and the national samples showed values similar or greater than $10 \mathrm{mg} / 100 \mathrm{~g}$. It follows that there is need for greater control and monitoring of temperature from capture to processing, to guarantee good quality to the final product, and to avoid risk of poisoning to the consumer. 
et al. (2004) alertam para o fato de que, além de as aminas serem estáveis ao calor, algumas descarboxilases permanecem ativas mesmo após tratamento térmico. Bactérias como Morganella morganii, Hafnia alvei, Proteus sp., Escherichia coli, Salmonela sp, são capazes de produzir a enzima histidina descarboxilase que, ao atuar sobre a histidina livre, a transformam em histamina. As bactérias produtoras de aminas biogênicas não fazem parte da microbiota normal intestinal, da pele ou brânquias dos peixes marinhos recém-capturados e, na maioria dos casos, se origina a partir da contaminação por práticas inadequadas de higiene durante a captura ou estão associadas ao ambiente marinho. Desse modo, é possível afirmar que a presença de histamina é um indicador de qualidade bacteriológica ruim. Quando o pescado, após-captura, é mantido em temperaturas que favoreçam o crescimento bacteriano, inicia-se um processo de degradação proteica com formação de histamina e outras aminas. LEITÃO et al. (1983) relatam a ampla distribuição de bactérias produtoras de histamina no ambiente marinho, particularmente na superfície e vísceras de espécies de pescado mais comumente comercializadas.

A histamina é termoestável e, segundo IENISTEA (1973), é apenas parcialmente destruída após três horas de aquecimento a $102^{\circ} \mathrm{C}$ ou noventa minutos a $116^{\circ} \mathrm{C}$ em conservas de sardinha de $250 \mathrm{~g}$, podendo estar presente em alimentos comercialmente esterelizados, considerados seguros sob o ponto de vista sanitário. Nessas condições, mesmo produtos enlatados de baixa acidez, como, por exemplo, o pescado, pode apresentar níveis tóxicos dessa amina, independente de quaisquer alterações evidentes no produto, após o processamento térmico. OLIVEIRA et al. (2004) relatam que a histamina em geral é estável em altas temperaturas, podendo estar presente em conservas de pescado, caso tenha sido formada antes do enlatamento.

Segundo HUSS (1997), a análise de histamina tem sido usada como índice de frescor do pescado, já que sua produção ocorre por meio de bactérias, porém peixes com grandes quantidades de histamina podem apresentar aparência e odor normais. NTZIMANI et al. (2008) comentam que a histamina é considerada o mais importante indicador de frescor do pescado. ARNOLD \& BROWN (1978) descrevem que não há produção de histamina em atum mantido a $1^{\circ} \mathrm{C}$ por 42 dias, indicando que a adequada refrigeração pode impedir a formação de histamina. Segundo GILBERT et al. (1980), peixes estocados a $0^{\circ} \mathrm{C}$ com gelo em fusão permanecem comestíveis por doze dias com uma concentração final de histamina entre 3 a $4 \mathrm{mg} / 100 \mathrm{~g}$, entretanto, sob temperatura de $12^{\circ} \mathrm{C} \mathrm{a}$ $20^{\circ} \mathrm{C}$ rapidamente são obtidas altas concentrações de histamina. VISCIANO et al. (2007) estudaram o efeito da temperatura sobre a produção de histamina em $S$. pilchardus e Engraulis encrasicolus e observaram que, após 24 horas em temperatura ambiente $\left(22^{\circ} \mathrm{C}\right)$, os valores médios observados foram de 146,5 mg/100 g em amostras em que se detectou essa amina logo após-captura.

BERSOT et al. (1996) recomendam que o pescado não seja mantido a temperaturas acima de $10^{\circ} \mathrm{C}$ por períodos longos, evitando com isso a multiplicação de bactérias formadoras de histamina, e alerta sobre a necessidade de se avaliar os métodos de obtenção de Sardinella aurita venezuelana. O propósito é comprovar os problemas ligados à captura e/ou armazenamento, pois foi verificado que $40 \%$ das amostras de sardinhas analisadas apresentaram, como resultados, teores de histamina acima de $10 \mathrm{mg} / 100 \mathrm{~g}$ de peixe.

O consumo de pescado com níveis elevados de histamina pode provocar intoxicação com sintomatologia bem variada, uma vez que a histamina é um potente vasodilatador. A dilatação é acompanhada por um aumento da permeabilidade capilar, possibilitando a perda de líquidos de vasos para o meio extracelular juntamente com proteínas plasmáticas e células vermelhas. Os sintomas podem aparecer alguns instantes após a ingestão do produto, variando de acordo com a quantidade consumida e a sensibilidade do indivíduo. Os sintomas principais são náuseas, vômitos, diarreia, dor abdominal, edema cutâneo, urticária, hipotensão, cefaleia, vertigens, rubor, ardência na boca. Em casos graves, em curto espaço de tempo podem ocorrer broncoespasmo, asfixia, dores respiratórias e choque (RUSSEL \& MARETIC, 1986).

O limite preconizado pela legislação brasileira, de 100 ppm (10mg/100 g), encontra-se no Regulamento Técnico de Identidade e Qualidade de Peixe Fresco Resfriado e Congelado, Portaria 185 (BRASIL, 1997). Em função de seus efeitos tóxicos, a histamina é a única amina biogênica com limite regulatório também na União Europeia de 100 mg/Kg (COMMISSION REGULATION, 2005). 
Tendo em vista as considerações feitas, o presente trabalho foi desenvolvido com o objetivo de investigar a ocorrência de histamina em conservas de sardinha elaboradas a partir de diferentes espécies, assim como fornecer subsídios à indústria pesqueira, aos laboratórios de Controle de Qualidade e aos órgãos de Saúde Pública, que poderão contar com mais um dado no julgamento da matéria-prima e do produto final.

\section{MATERIAL E MÉTODOS}

Foram analisadas 122 amostras de sardinha em conserva, em óleo comestível adquiridas diretamente das Indústrias A, B e C, logo após o processo de esterilização comercial. Considerou-se cada lata uma amostra.

QUADRO 1. Informações relativas aos lotes, indústrias, número de amostras analisadas e espécies de sardinhas

\begin{tabular}{|c|c|c|c|}
\hline Lotes & Indústrias & $\mathrm{n}$ & Espécies \\
\hline Lote 1 & $\mathrm{A}$ & 20 & Sardinella aurita \\
\hline Lote 2 & $\mathrm{B}$ & 30 & Sardina pilchardus \\
\hline Lote 3 & $\mathrm{A}$ & 10 & Sardinella brasiliensis \\
\hline Lote 4 & $\mathrm{B}$ & 15 & Sardinella brasiliensis \\
\hline Lote 5 & $\mathrm{C}$ & 35 & Sardinella brasiliensis \\
\hline Lote 6 & $\mathrm{C}$ & 12 & S.pilchardus, S. brasiliensis \\
\hline
\end{tabular}

Os lotes foram compostos por amostras relacionadas ao container que transportava a matéria-prima até a indústria.

Após o descarregamento dos containers, o pescado foi acondicionado em câmara fria com temperatura próxima a $2^{\circ} \mathrm{C}$, para posterior processamento. Após descongelamento, submeteram-se as amostras de S. pilchardus e $S$. aurita e de sardinha fresca nacional à avaliação sensorial do pescado, com o intuito de se obter informações sobre a qualidade do peixe que estava sendo enlatado. Realizou-se essa avaliação de acordo com o RIISPOA (BRASIL, 2007) e RABELO
(1988), visando classificar a qualidade de acordo com as características sensoriais das sardinhas importadas evisceradas e sem cabeça, que foram avaliadas de acordo com os atributos textura e odor. Após a avaliação, toda a matéria-prima foi considerada, em sua maioria, de boa qualidade, à exceção das que compuseram o lote 5 , que apresentaram características consideradas de qualidade regular, apesar de ser recomendado seu processamento.

As sardinhas processadas nas indústrias A e $\mathrm{B}$ foram mantidas refrigeradas e adequadamente em torno de $4^{\circ} \mathrm{C}$ até o pré-cozimento. $\mathrm{Na}$ indústria $\mathrm{C}$, o processamento ocorreu em temperatura que variou de 10 a $24^{\circ} \mathrm{C}$. A matéria-prima importada da Venezuela fez parte de um lote na qual a temperatura de refrigeração pós-captura manteve-se em torno de $4^{\circ} \mathrm{C}$ até seu congelamento. A manipulação após o descongelamento obedeceu aos mesmos cuidados de refrigeração já mencionados, tendo sido realizado um monitoramento da temperatura e avaliada a qualidade da matéria-prima para posterior enlatamento. O lote 6 foi formado por amostras mantidas propositalmente por 12 e 24 horas em temperatura ambiente para, posteriormente, entrarem no fluxo de produção. Produziram-se seis latas com S. pilchardus e seis com $S$. brasiliensis, processadas na indústria $\mathrm{C}$.

A técnica utilizada para determinação de histamina em $\mathrm{mg} / 100 \mathrm{~g}$ foi a cromatografia em camada delgada descrita por SCHUTZ, CHANG \& BJELDANES (1976), com pequenas modificações.

Para o preparo das amostras, após limpas e identificadas, procedeu-se à abertura das latas e esgotou-se o líquido de cobertura (óleo vegetal), que foi vazado, e por leve compressão da própria tampa sobre as sardinhas, esgotou-se o óleo restante. Uma porção de músculo foi retirada com espátula e homogeneizada com auxílio de gral e pistilo, coletando-se $1 \mathrm{~g}$ dessa porção em tubo de ensaio tomando-se o cuidado para evitar transferências de óleo. Adicionaram-se $2 \mathrm{~mL}$ de metanol e aqueceu-se em banho-maria sob agitação até a fervura, deixando depois em repouso, até que uma porção límpida de sobrenadante fosse visualizada.

No preparo das soluções de histamina, pesaramse $165,8 \mathrm{mg}$ de histamina $2 \mathrm{HCI}$ em $100 \mathrm{~mL}$ de metanol $(1 \mathrm{mg} / \mathrm{mL})$ (SCHUTZ et al., 1976). Esse padrão equivalia ao teor de $1 \mathrm{mg} / 100 \mathrm{~g}$ de peixe quando aplicado na quantidade de $1 \mu \mathrm{L}$. Para o preparo da solução 
ninhidrina, dissolveu-se $0,3 \mathrm{~g}$ de reagente em $100 \mathrm{~mL}$ de metanol.

A fase móvel constituiu-se por uma mistura de $20 \mathrm{~mL}$ de acetona, e $1 \mathrm{~mL}$ de hidróxido de amônia colocada em uma cuba retangular bem vedada.

As placas de sílica-gel em poliéster (SIGMA T-6770) foram cortadas, tomando-se cuidado para não desprender a camada de sílica.

Fez-se uma leve marcação a lápis a $1,5 \mathrm{~cm}$ da parte inferior da placa e marcados os locais onde seriam aplicadas as amostras e os padrões. O tamanho das placas utilizadas foram $5 \times 10$ e 10x10 cm. Utilizaram-se três padrões em cada placa, de 2, 5 e $10 \mathrm{mg} / 100 \mathrm{~g}$.

Aplicaram-se $10 \mu \mathrm{L}$ do sobrenadante límpido das amostras com auxílio de micropipetas, secando-se a placa com calor fluente entre as aplicações (mancha em torno de $0,5 \mathrm{~cm}$ de diâmetro).

Para o padrão de histamina, utilizou-se o mesmo procedimento, com auxílio de uma microsseringa de $10 \mu \mathrm{L}$, aplicando-se $2 \mu 1$ para o padrão equivalente a $2 \mathrm{mg} / 100 \mathrm{~g}, 5 \mu \mathrm{L}$ para o padrão equivalente a $5 \mathrm{mg} / 100 \mathrm{~g}$ e $10 \mu \mathrm{L}$ para o padrão equivalente a $10 \mathrm{mg} / 100 \mathrm{~g}$.

Após o preparo, a placa foi inserida no interior da cuba cromatográfica, com auxílio de uma pinça, fechando-a e aguardando até completar a "corrida", ou seja, subida do solvente até aproximadamente $2 \mathrm{~cm}$ da parte superior da placa, quando então a placa foi retirada e secada em calor fluente até completa eliminação dos resíduos de amônia.

Segurando a placa com uma pinça pela extremidade superior, aspergiu-se uniformemente, com o auxílio do compressor, um reagente cromogênico para detecção das manchas ou revelação da placa usando a solução de ninhidrina $0,3 \%$ em metanol. A placa foi secada e aquecida, até a obtenção de uma boa visualização das manchas correspondentes aos padrões de histamina, comparando-se estes, visualmente, com as manchas de mesmo deslocamento das amostras. Estimaram-se os valores prováveis do conteúdo de histamina em $\mathrm{mg} / 100 \mathrm{~g}$ de peixe pela intensidade das amostras.

\section{RESULTADOS E DISCUSSÃO}

Relativamente às vinte amostras pertencentes ao lote 1 , em quinze (75\%) não se detectou histamina, enquanto cinco $(25 \%)$ apresentaram teores de histamina abaixo de $5 \mathrm{mg} / 100 \mathrm{~g}$.
No lote 2, que totalizou trinta amostras, quatro $(13,34 \%)$ apresentaram teor de histamina abaixo de 5 $\mathrm{mg} / 100 \mathrm{~g}$, enquanto que nas outras $26(86,66 \%)$ não foi detectada histamina.

No lote 3 , que totalizou dez amostras, encontraram-se duas (20\%) com aproximadamente $5 \mathrm{mg} / 100 \mathrm{~g}$, cinco $(50 \%)$ com aproximadamente $10 \mathrm{mg} / 100 \mathrm{~g}$ e três $(30 \%)$ com teor de histamina acima de $10 \mathrm{mg} / 100 \mathrm{~g}$.

No lote 4 , que totalizou quinze amostras, duas $(13,33 \%)$ apresentaram teores de histamina de 5 $\mathrm{mg} / 100 \mathrm{~g}$, oito $(53,33 \%)$ entre 5 e $10 \mathrm{mg} / 100 \mathrm{~g}$ e as outras cinco amostras $(33,34 \%)$ mais de $10 \mathrm{mg} / 100 \mathrm{~g}$.

O lote 5 apresentou duas amostras $(5,71 \%)$ com teores de $5 \mathrm{mg} / 100 \mathrm{~g}$ e seis $(14,14 \%)$ entre cinco e 10 $\mathrm{mg} / 100 \mathrm{~g}$. As outras $27(77,14 \%)$ apresentaram teores acima de $10 \mathrm{mg} / 100 \mathrm{~g}$.

O lote 6 apresentou níveis de histamina acima de $10 \mathrm{mg} / 100 \mathrm{~g}$ de sardinhas em todas as amostras.

A variação nos teores de histamina ocorrida principalmente nos lotes três e quatro sugere que o frio não foi uniformemente distribuído aos peixes nos barcos, câmaras frias e em outras etapas do processamento tecnológico. Isto fez com que alguns exemplares fossem resfriados adequadamente e outros permanecessem em condições favoráveis ao crescimento bacteriano e, consequente, produção de histamina.

Não foi observada diferença significativa $(p>0,05)$ entre as três espécies que apresentavam as mesmas condições de processamento.

Diversos autores relatam que não há correlação direta entre produção de histamina e alterações sensoriais do pescado, ou seja, a presença de histamina não pode ser considerada, isoladamente, um indicador universal de decomposição do pescado. Entre eles, BERSOT et al. (1996) consideram que não há uma correlação direta entre a produção de histamina e as alterações sensoriais e que a histamina pode alcançar níveis tóxicos mesmo antes que o pescado seja rejeitado sensorialmente, embora o inverso também possa ocorrer. Para certificar a qualidade do pescado, é necessário avaliar outros parâmetros, além de outras aminas biogênicas, segundo relatos.

Os resultados obtidos no presente estudo encontram respaldo nos trabalhos de ARNOLD \& BROWN (1978) e BALDINI (1982), principalmente, em relação aos dados dos lotes 3 e 4 , que apresentaram teores de 
histamina acima de $10 \mathrm{mg} / 100 \mathrm{~g}$ em três e cinco latas respectivamente, mesmo a matéria-prima apresentando características sensoriais aceitáveis. No entanto, o lote 5, muito embora mostrasse características sensoriais que recomendavam sua utilização, apresentou 27 (77,14\%) das amostras com teores de histamina muito acima de $10 \mathrm{mg} / 100 \mathrm{~g}$.

Teores de histamina abaixo de $5 \mathrm{mg} / 100 \mathrm{~g}$ foram encontrados em todas as amostras dos lotes 1 e 2 , considerados como sardinhas de boa qualidade, após desembarque na indústria. Já os lotes 3 e 4, também considerados de boa qualidade, oito amostras, ou seja, $40 \%$ do total das latas, revelaram teores de histamina acima do recomendado pela Legislação Internacional (10 mg/100 g).

LUTEN (1981), ao analisar trinta latas de sardinha, encontrou resultados que variaram entre menores que $1 \mathrm{mg} / 100 \mathrm{~g}$ e $100 \mathrm{mg} / 100 \mathrm{~g}$ de histamina. Desse total, $13 \%$ apresentaram valores acima de $10 \mathrm{mg} / 100 \mathrm{~g}$. No presente estudo, 31,81\% das amostras apresentaram teor acima de $10 \mathrm{mg} / 100 \mathrm{~g}$.

NOVAES (1989), em estudo realizado com sardinhas armazenadas a $4^{\circ} \mathrm{C}$ por oito dias, encontrou teor de histamina de 4,9mg/100g. No presente trabalho, nos quatro primeiros lotes, nos quais a temperatura de manipulação estava em torno de $4^{\circ} \mathrm{C}, 54(72 \%)$ das amostras apresentaram teor de histamina abaixo de $5 \mathrm{mg} / 100 \mathrm{~g}$ de sardinha. Ainda segundo NOVAES (1989), sardinhas (S. brasiliensis) armazenadas a $0^{\circ} \mathrm{C}$ durante dez dias apresentavam valores de histamina inferiores a $1 \mathrm{mg} / 100 \mathrm{~g}$. Nos peixes armazenados a $4^{\circ} \mathrm{C}$, o valor máximo foi de $4,9 \mathrm{mg} / 100 \mathrm{~g}$ no oitavo dia. Os peixes armazenados à temperatura ambiente apresentaram teores de histamina em torno de $5 \mathrm{mg} / 100 \mathrm{~g} \mathrm{em}$ apenas doze horas.

BERSOT et al. (1996), após analisarem noventa amostras de sardinha enlatada ( $S$. aurita), verificaram que $36(40 \%)$ apresentavam níveis de histamina entre 10 e $100 \mathrm{mg} / 100 \mathrm{~g}$ e sugeriram que esses resultados eram devidos a falhas na captura e no armazenamento dos peixes. Os resultados obtidos neste estudo corroboram as argumentações do autor, pois, no lote 1 , $100 \%$ das amostras apresentaram teores de histamina menor que $5 \mathrm{mg} / 100 \mathrm{~g}$. Vale ressaltar que este lote foi composto por amostras oriundas de uma empresa que tinha a preocupação em manter a temperatura de $4^{\circ} \mathrm{C}$ desde a captura dos peixes até o processamento.
OLIVEIRA et al. (2004) analisaram 45 latas de sardinha em conserva e observaram a presença de histamina em todas as amostras. Os valores variaram entre 3,35 e $346,44 \mathrm{mg} / \mathrm{kg}$, com $13,33 \%$, superando o limite preconizado pela legislação brasileira, de 10 mg/100 g (BRASIL, 1997).

Comparando os resultados apresentados na literatura consultada com os obtidos neste estudo pode-se afirmar que os níveis encontrados são similares e, em alguns casos, superiores, demonstrando que algumas conservas de sardinha podem representar um perigo para o consumidor.

Os resultados dos lotes 5 e 6 reforçam a relação entre a formação de histamina e temperatura elevada. Ao mesmo tempo, não parecem ligar esta formação à espécie. Mesmo constituído de matéria-prima de boa qualidade, o lote 5 foi processado em temperatura que variou de 10 a $24^{\circ} \mathrm{C}$. Já o lote 6 foi processado em temperatura ambiente. No lote 5, os níveis de histamina estiveram acima de $10 \mathrm{mg} / 100 \mathrm{~g}$ em $77,15 \%$ das amostras, enquanto $22,85 \%$ apresentaram menos de 10 $\mathrm{mg} / 100 \mathrm{~g}$ de sardinha. No entanto, o lote 6 apresentou, em $100 \%$ das amostras, teores de histamina bem acima de $10 \mathrm{mg} / 100 \mathrm{~g}$.

Apesar de serem processados em temperaturas abaixo de $10^{\circ} \mathrm{C}$, os lotes 3 e 4 apresentaram, em $30 \%$ e 33,34\%, respectivamente, das amostras, níveis de histamina acima de $10 \mathrm{mg} / 100 \mathrm{~g}$, portanto acima do limite nacional (BRASIL, 1997).

SOARES \& GLORIA, (1984) pesquisando a presença de histamina em sardinha enlatada em Belo Horizonte, MG, obtiveram resultado positivo em $91 \%$ das amostras que apresentaram teores que variaram de 0,12 a $3,98 \mathrm{mg} / 100 \mathrm{~g}$, porém sugeriram que, teoricamente, não eram suficientes para causar intoxicação.

Segundo SIKORSKI (1990), RUSSEL \& MARETIC (1986) e BALDRATI et al. (1980), temperaturas de $18-20^{\circ} \mathrm{C}$ são predisponentes à formação de histamina. Esta afirmação encontra respaldo nos resultados do presente estudo, pois, nos lotes 5 e 6 , cuja manipulação ocorreu em temperatura acima de $10^{\circ} \mathrm{C}, 77,15 \%$ e $100 \%$, respectivamente, das amostras apresentaram teor de histamina superior a 10 $\mathrm{mg} / 100$ g. Por outro lado, os lotes 1 e 2, nos quais a manipulação se deu em temperaturas em torno de $4{ }^{\circ} \mathrm{C}, 100 \%$ das amostras apresentaram menos de 5 $\mathrm{mg} / 100 \mathrm{~g}$ de sardinha. 
Portanto, pode-se afirmar que a temperatura interfere na formação da histamina, independentemente da espécie de sardinha.

SIKORSKI (1990) e IENISTEA (1973) afirmam que a sardinha pode apresentar quantidades de histidina livre comparáveis aos peixes da família Scombridae. Já LEITÃO et al. (1983b) consideram elevados os níveis de $196,6 \mathrm{mg} / 100 \mathrm{~g}$ de histidina livre encontrado em sardinhas. Em parte, este estudo confirma as observações dos autores, principalmente levando em consideração os resultados dos lotes 5 e 6 , nos quais a temperatura elevada facilitou a transformação da histidina livre em histamina.

Comparando os dados citados por ABABOUCH et al. (1986), que também evidenciaram alta porcentagem de conservas de sardinhas com teores acima de $10 \mathrm{mg} / 100 \mathrm{~g}$ nas amostras obtidas em mercado varejista, com os encontrados neste trabalho, podese afirmar que são semelhantes, principalmente em relação aos resultados dos cinco primeiros lotes, nos quais a presença de histamina ocorreu em $62,72 \%$ das amostras, e do lote $6,100 \%$ das amostras, cujos teores estiveram acima de $10 \mathrm{mg} / 100 \mathrm{~g}$, considerados tóxicos e preocupantes.

\section{CONCLUSÕES}

- As conservas enlatadas de sardinhas devem ser incluídas no grupo dos alimentos que apresentam possibilidades de intoxicação por histamina.

- $\mathrm{O}$ abuso de temperaturas em qualquer fase de manipulação da sardinha para a elaboração de conserva, desde a captura até o processamento, possibilita a formação de histamina ou aumento dos seus teores nas conservas.

- A presença de histamina no pescado independe das características sensoriais iniciais, das áreas de capturas e das espécies.

- As indústrias pesqueiras necessitam monitorar a temperatura de conservação da matéria-prima desde a captura até o processamento final, procurando manter sempre temperaturas abaixo de $5^{\circ} \mathrm{C}$, excetuando o tratamento térmico, visando impedir a formação de histamina.

\section{Para HISTAMINA}

Em 184,08 (PM) de histamina dihidrocloride

$$
\mathrm{X}
$$

$\rightarrow \mathbf{1 1 1}, \mathbf{1 5}$ de histamina

$\rightarrow 1 \mathrm{mg}$ de histamina $\mathrm{X}=1,6561 \mathrm{mg}$ de histamina dihidrocloride

Para $100 \mathrm{ml}$ de solução-padrão $\rightarrow 165,61 \mathrm{mg}$ do sal (cada ml de solução terá $1 \mathrm{mg}$ de histamina)

Como o padrão tem $99 \%$ de pureza:

$99 \mathrm{~g}$ de histamina dihidrocloride $\rightarrow 100 \mathrm{~g}$ do sal

$165,51 \mathrm{mg} \quad \rightarrow \mathrm{x}=167,28 \mathrm{mg}$

Solução-padrão: 167,28 mg de histamina dihidrocloride em $100 \mathrm{ml}$ de solução 


\section{REFERÊNCIAS}

ABABOUCH, L.; ALAQUI, M. M.; BUSTA, F. F. Histamine levels in commercially processed fish in Marroco. Journal of Food Protection, v. 49, n. 11, p. 904-908, 1986.

ARNOLD, S. H.; BROWN, W. D. Histamine (questionable) toxicity from fish products. Advances in Food Research, v. 24, p. 113-154, 1978.

BALDINI, V. L. S. Aminas biogênicas e a deterioração do pescado. Boletim do ITAL, v. 24, p. 389-402, 1982.

BALDRATI, G.; FORNARI, M.B.; SPOTTI, E.; INCERTI, I. Effect of temperature on histamine formation in fish rich in free histidine. Industria Conserve, v. 55 n. 2, p. 114-122, 1980.

BERSOT, L. S.; SÃO CLEMENTE, S. C.; SANTOS, N. N. Avaliação dos teores de histamina em sardinha enlatada (Sardinella aurita Valenciennes, 1847). Higiene Alimentar, São Paulo, v. 10, n. 45, p. $38-43,1996$.

BRASIL. Ministério da Agricultura, Pecuária e Abastecimento. Portaria $n^{\circ} 185$, de 13 de maio de 1997. Aprova o Regulamento Técnico de Identidade e Qualidade de Peixe Fresco (Inteiro e Eviscerado). Diário Oficial da República Federativa do Brasil, Brasília, DF, 1997. p. 6.

Ministério da Agricultura Pecuária e Abastecimento. Regulamento da Inspeção Industrial e Sanitária de Produtos de Origem Animal - R.I.I.S.P.O.A. Departamento Nacional de Inspeção de Produtos de Origem Animal. Diário Oficial da República Federativa do Brasil, Brasília, DF, 2007.

COMMISSION REGULATION (EC) 2073/2005, 15 nov. 2005. Microbiological criteria for foodstuffs. Official Journal of European Union, 2005. L338, p. 1-26.

GILBERT, R. J.; HOBBS, G.; MURRAY, C. K.; CRUICKSHANK, J. G.; YOUNG, S. Scombrotoxic fish poisoning: features of the first 50 incidentes to be reported in Britain (1976-9). British Medical Journal, v. 281, n. 6233, p. 71-72, 1980.

HUSS, H. H. Garantia de qualidade dos produtos da pesca. Departamento de Investigação dos Produtos da Pesca. Ministério da Agricultura e da Pesca. Dinamarca. FAO. Documento Técnico sobre as Pescas 334. Roma, 1997.

IENISTEA, C. Significance and detection of histamine. In: HOBBS, B.C.; CHISTIAN, J. H. B. The microbiological safety of food. London: Academic Press, 1973. p. 327-343.
LEITÃO, M. F. F.; BALDINI, V. L. S.; SALLES, A. M. Histamina em pescado e alimentos industrializados. Coletânea do ITAL, v. 13, p. $123-130,1983$.

LUTEN, J. B. Na automated fluorimetric method for the determination of histamine in canned fish products. Journal of Food Science, v. 46, n. 3, p. 958-959, 1981.

NOVAES, C. L. P. Teores de histamina em sardinha verdadeira em temperatura de $0^{\circ} \mathbf{C}, 4^{\circ} \mathbf{C}$ e ambiente. Niterói, 1989. 99 f. Tese (Mestrado em Higiene Veterinária e Processamento Tecnológico de Produtos de Origem Animal) - Faculdade de Veterinária, Universidade Federal Fluminense, 1989.

NIZIMANI, A. G.; PALEOLOGOS, E. K.; SAVVAIDIS, I. N.; KONTOMINAS, M. G. Formation of biogenic amines and relation to microbial flora and sensory changes in smoked turkey breast fillets under various packaging conditions at $4{ }^{\circ} \mathrm{C}$. Food Microbiology, v. 25, p. 509-517, 2008.

OLIVEIRA, H. A. C.; SILVA, H. C. M.; SAMPAIO, A. H.; VIANNA, F. A.; SALTER-SAMPAIO, S. Determinação de histamina por cromatografia líquida de alta eficiência de fase reversa em atum e sardinha enlatados. Revista Ciência Agronômica, v. 35, p. 179-188, 2004.

RABELO, A. M. O. Métodos sensoriais para análise do pescado: seminários sobre controle de qualidade do pescado. Santos: SBCTA/ITAL, 1988. p.106-116.

RUSSEL, F. E.; MARETIC, Z. Scombroid Poisoning: mini review case histories. Toxicon, v. 24, n. 10, p. 967-973, 1986.

SCHUTZ, D. E.; CHANG, G. W.; BJELDANES, L. F. Rapid thin layer chromatographic method for the detection of histamine in fish products. Journal of AOAC, v. 59, p. 1224-1225, 1976

SIKORSKI, Z. E. Tecnologia de los productos del mar: recursos, composicion nutritiva y conservacion. 5. ed. Zaragoza: Acribia, 1990. $330 \mathrm{p}$.

SOARES, V. F. M.; GLÓRIA, M. B. A. Histamine levels in canned fish available in Belo Horizonte, Minas Gerais, Brasil. Journal of Food Composition and Analysis, v. 7, n. 1/2, p. 102-109, 1994.

VISCIANO, P.; CAMPANA, G.; ANNUNZIATA, L.; VERGARA, A.; IANIERI, A. Effect of storage temperature on histamine formation in Sardina pilchardus and Engraulis encrasicolus after catch. Journal of Food Biochemistry, v. 31, p. 577-588, 2007. 